\title{
Modernizing device regulation
}

\section{Citation}

Garber, Alan M. 2010. Modernizing device regulation. New England Journal of Medicine 362 , 13:1161-1163.

\section{Published Version}

doi:10.1056/NEJMp1000447;http://www.nejm.org/doi/full/10.1056/NEJMp1000447

\section{Permanent link}

http://nrs.harvard.edu/urn-3:HUL.InstRepos:11595666

\section{Terms of Use}

This article was downloaded from Harvard University's DASH repository, and is made available under the terms and conditions applicable to Other Posted Material, as set forth at http:// nrs.harvard.edu/urn-3:HUL.InstRepos:dash.current.terms-of-use\#LAA

\section{Share Your Story}

The Harvard community has made this article openly available.

Please share how this access benefits you. Submit a story.

\section{Accessibility}




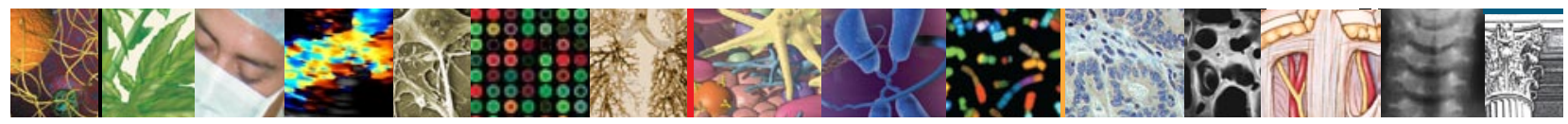 The NEW ENGLAND JOURNAL of MEDICINE}
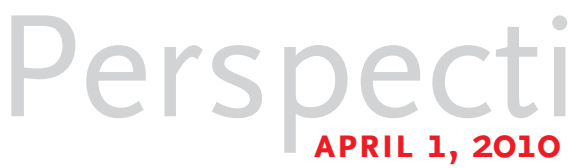

\section{Modernizing Device Regulation}

Alan M. Garber, M.D., Ph.D.

\section{The Food and Drug Administration (FDA) is known for its rigor in regulating drugs, not devices. That may be about to change. In recent years, well-publicized device recalls and lawsuits}

have led to complaints that the FDA does not do enough to keep unsafe devices off the market. The failure of some devices, such as implantable defibrillators, could pose deadly risks.

Fundamental differences between devices and drugs have important implications for FDA regulation. A typical device is an engineered product, rather than a chemical compound like a conventional drug or a biologic agent. The effects of a minor modification in the structure of a drug are rarely predictable enough to obviate the need for clinical trials. In contrast, the effects of modifications of devices are often predictable. A screw can be changed, a battery redesigned or replaced with a longer-lasting alternative. A series of small changes, however, can collectively lead to entirely new functions and, potentially, risks. Pacemakers, for example, have much more sophisticated capabilities than they did 20 years ago, and arguably, the defibrillation and cardiac-resynchronization capabilities of devices today are the result of multiple incremental changes in pacemaker technology. At what point does a modification of a device warrant an entirely new approval process? And who should make that decision?

Waiting until a device is frozen in final form before seeking
FDA approval could lead to very long delays in product introduction and discourage companies from making improvements after approval. Without new clinical studies, it is not easy to determine whether an incremental change in a device increases risk or impairs effectiveness. But treating every modification as the equivalent of a new drug would make incremental improvements prohibitively time-consuming.

For regulatory purposes, the FDA classifies medical devices into three categories. Most class I and II devices, which are considered low risk, require only a "premarket notification" or a $510(\mathrm{k})$ clearance to be marketed. Clinical trials to show safety and efficacy are unnecessary for the $510(\mathrm{k})$ clearance. Class III devices, which are considered high risk, can receive a $510(\mathrm{k})$ exemption if they can be shown 


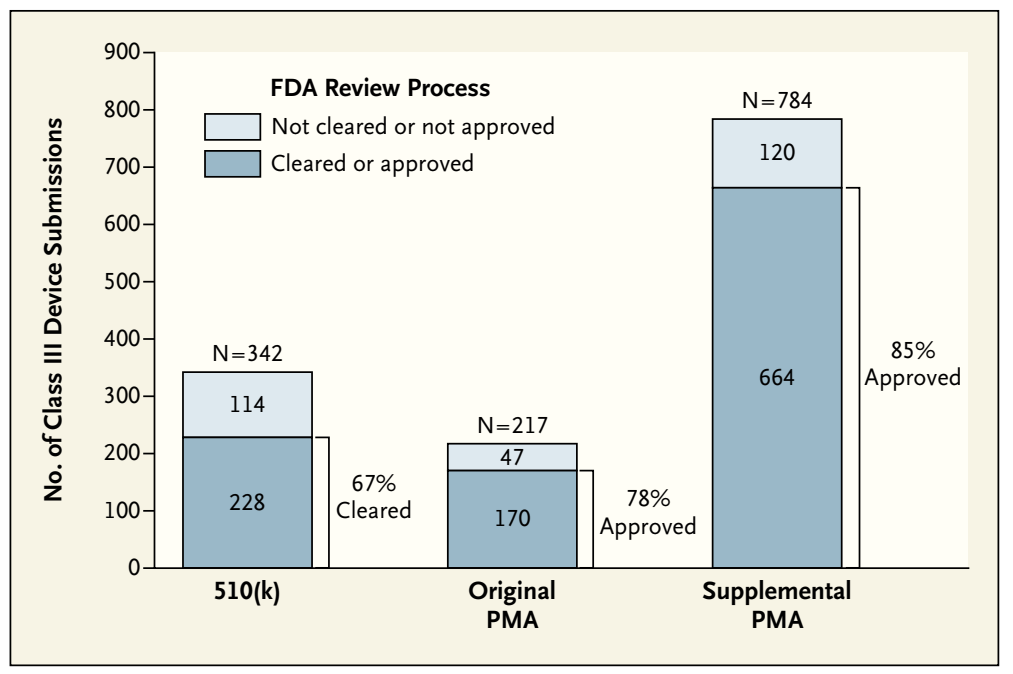

Decisions about Class III Device Submissions by the FDA in Fiscal Years 2003-2007, According to FDA Review Process.

The data pertain to FDA review decisions made through the $510(\mathrm{k})$ and premarketapproval (PMA) processes from October 1, 2002, through September 30, 2007, for class III devices. Devices that were not cleared or not approved include $510(\mathrm{k})$ submissions that the FDA found to be not substantially equivalent to a marketed device or that were withdrawn, as well as PMA submissions that were withdrawn; the FDA did not deny approval of any PMA submissions during this period. The FDA considers submissions to be withdrawn voluntarily if the applicant is unable to provide the information necessary to support approval within 180 days. Adapted from a Government Accountability Office Medical Device Premarket Review based on FDA data.

to be "substantially equivalent to [a device] legally in commercial distribution in the United States." ${ }^{1}$ High-risk devices that are not eligible for such an exemption must undergo a full premarket-approval (PMA) evaluation. Like the new-drug application process, PMA requires results from clinical studies showing a product's safety and efficacy.

Criticisms of the FDA's scrutiny of devices center on two major claims: that the $510(\mathrm{k})$ exemption is used too freely and that the full PMA review is not stringent enough. For instance, the FDA argued last year that under the previous administration, the $510(\mathrm{k})$ process was used inappropriately to allow the Menaflex knee implant to be marketed. ${ }^{2}$ And the Government Accountability Office reported that in could fracture, patients faced a wrenching dilemma: they could undergo risky procedures to replace the leads or, as the company advised, leave them alone and simply live with the ever-present danger of sudden, catastrophic failure. Litigation ensued.

Product-safety litigation has long complemented regulatory oversight in deterring the sale of unsafe medical devices. But in its 2008 decision in Riegel $v$. Medtronic, the U.S. Supreme Court ruled that because federal law preempts state laws, makers of medical devices that have received FDA approval cannot be sued over product defects in state courts (where tort litigation must take place). The suit had been brought over a balloon catheter that burst while being inserted into a coronary artery, but the ruling applies to all devices that have undergone the PMA process. Consumersafety advocates and other critics of FDA regulation of medical devices, along with members of Congress, were dismayed that harmful devices that have passed any FDA review - even an inadequate one - will no longer be subject to the threat of legal action in state courts.

The loss of the ability to sue might have been less troubling if the PMA process were consistent and stringent. But critics argue that it is neither. A recent study concluded that of 78 "highrisk" cardiovascular devices that were approved through a PMA application between 2000 and 2007, less than one third had been subjected to a randomized trial. ${ }^{3}$ Only $5 \%$ of the devices had undergone two or more blinded, randomized studies.

The Obama administration would have been under pressure 
to reevaluate device regulation even if the Riegel decision had not been issued. The reevaluation is now an urgent priority. The recently issued strategic priorities of the FDA's Center for Devices and Radiological Health indicate that improvements in the review process will be high on the agenda. ${ }^{4}$ How might the FDA best approach its role as a device regulator?

A more rigorous device-approval process - involving more selective application of the $510(\mathrm{k})$ exemption and more consistent application of requirements for well-designed trials of sufficient size and duration - would remedy some of the problems identified by critics. If the PMA process were more transparent and its specific requirements were fully elucidated in advance, it would also respond to industry's criticisms that it is unpredictable.

Nevertheless, a revised preapproval process is unlikely to solve all the problems posed by existing approaches to device regulation. More rigorous preapproval studies cannot provide absolute assurances of long-term safety or effectiveness. Risks associated with devices that become evident only after months or years of use would not be detected even in a more comprehensive premarketing evaluation. And more demanding evidence standards will raise the cost of bringing a product to market - an obstacle that might be of limited importance for large device companies but could be insuperable for undercapitalized start-up firms similar to those that have been the source of many device innovations.

Much more could be done to learn about experiences with devices after they are approved. The FDA's system of postmarketing surveillance has never been as comprehensive, even for drugs, as the agency would like. Followup drug studies that the FDA demands are not always completed, many are conducted or reported on long after the designated deadlines, ${ }^{5}$ and the FDA has limited ability to remove poor products from the market. The agency's capabilities in the device arena are no greater; in fact, it is often more difficult to identify a device that has already been implanted in patients than it is to determine which drugs they have received.

Medical devices hold tremendous potential for both good and harm. A modernized and more appropriate approach to their regulation should not be limited to better preapproval evaluation. The payoff from increased investments in postapproval studies would be substantial. The collection of postapproval data can be facilitated through the pooling of data from electronic health records, which offers the opportunity for researchers and regulators to learn from the experience of large numbers of patients, with far more extensive clinical detail than has been available from observational databases. Longer follow-up periods would enable the FDA to detect delayed benefits and harms. And studies based on real-world experience would do a better job of evaluating effectiveness for typical patients. This is the right time to institute a more comprehensive approach to the postapproval monitoring and analysis of the safety and effectiveness of medical devices.

Disclosure forms provided by the author are available with the full text of the article at NEJM.org.

From the Veterans Affairs Palo Alto Health Care System, Palo Alto; and the Center for Primary Care and Outcomes Research and the Center for Health Policy, Stanford University, Stanford - both in California.

This article (10.1056/NEJMp1000447) was published on March 24, 2010, at NEJM.org.

1. Food and Drug Administration. Overview of device regulation. 2010. (Accessed March 11,2010 , at http://www.fda.gov/Medical Devices/DeviceRegulationandGuidance/ Overview/default.htm.)

2. Mundy A, Favole JA. FDA rips approval of medical device. Wall Street Journal. September 25, 2009:A4.

3. Dhruva SS, Bero LA, Redberg RF. Strength of study evidence examined by the FDA in premarket approval of cardiovascular devices. JAMA 2009;302:2679-85. [Erratum, JAMA 2010;303:422.]

4. Center for Devices and Radiological Health. CDRH FY 2010 strategic priorities. Washington, DC: Food and Drug Administration, 2010. (Accessed March 11, 2010, at http://www .fda.gov/downloads/AboutFDA/Centers Offices/CDRH/CDRHVisionandMission/ UCM197648.pdf.)

5. Independent evaluation of FDA's Prescription Drug User Fee Act - evaluations and initiatives: CDER technical support and analysis: final report on the PMR/PMC backlog review. Washington, DC: Food and Drug Administration, 2009. (Accessed March 11, 2010, at http://www.fda.gov/downloads/ Drugs/GuidanceComplianceRegulatory Information/Post-marketingPhaselV Commitments/UCM181135.pdf.)

Copyright (C) 2010 Massachusetts Medical Society. 